\title{
Effect of Bacteria Exopolysaccharide on Milk Gel Formation
}

\author{
Ratmawati Malaka ${ }^{1}$, Tomio Ohashi ${ }^{2}$, Sudirman Baco ${ }^{1}$ \\ ${ }^{1}$ Department of Animal Production, Faculty of Animal Science, Hasanuddin University, Makassar, Indonesia \\ ${ }^{2}$ Department Biological Resource Science, Faculty of Agriculture, Miyazaki University, Miyazaki, Japan \\ Email: malaka_ag39@yahoo.co.id
}

Received August 2013

\begin{abstract}
The main objective of this study was to determine effect of exopolysaccharide (EPS) from bacteria on formation of milk gel. Milk gel was made from 10\%, 15\% and 20\% Reconstituted Skim Milk (RSM). EPS at different concentrations $(0 \%, 0.2 \%, 0.4 \%, 0.6 \%, 0.8 \%$ and $1.0 \%$ according to our previous study) were added to RSM, heated at $60^{\circ} \mathrm{C}$ for 30 minute and $85^{\circ} \mathrm{C}$ for 30 second and cooled to $5^{\circ} \mathrm{C}$ before viscosity and $\mathrm{pH}$ were examined using viscometer and $\mathrm{pH}$-meter. Viscosity was dependent on the concentrations of skim milk, increasing as the concentration of RSM increased. Lower concentration of EPS, viscosity showed a slight increase, but at $0.4 \%$ EPS, viscosity of milk gel increased rapidly and continued to increase up to $1 \%$. Microstructure was determined using scanning electron microscope to evaluated milk gel formation. Interaction between milk protein and EPS was showed as network aggregate one and another. EPS function as binding agent between one molecule of casein and another. These results indicated that EPS could be used to increase quality of milk gel.
\end{abstract}

Keywords: Exopolysaccharide; Viscosity; Milk Gel

\section{Introduction}

Many processing problems, such as low viscosity or high syneresis, which occur during milk product manufacture, are often solved by increasing the total solid or adding stabilizers, such as modified starch, carrageenan, guar gum, pectin, gelatin and sodium caseinate. However, some feel that these addictives adversely affect the true milk product (yoghurt, cheese, ice cream) taste, aroma and mouth feel.

The name exopolysaccharide (EPS) is a general term for all these form of bacterial polysaccharide found outside the cell wall (Sutherland, 1977). EPS isolated from bacteria have been claimed to have antitumor activity. On the other hand a number of polysaccharide bacteria indicated have potent inhibitory effect on AIDS infection (Yoon et al., 1996). Microbial polysaccharides are also produced as food addictive that can use as stabilizer in fermented milk and increase the quality of milk product (Malaka, 1997).

Interaction between milk protein and polysaccharide is important in relation with the milk gel quality. Electrostatic attraction between charged polysaccharide and protein molecular is generally the major driving force for these interactions, some of mixture polysaccharide and milk showed that k-casein particle are absorbed on the polysaccharide chain (Snoeren et al., 1976), EPS also stabilizes $\beta$-casein and para casein.

Although EPS have been investigated as food stabilizer, there is little information exist on how effect of EPS on milk gel formation.

\section{Materials and Methods}

\section{Preparation of Milk Gel}

Milk gel was made from 10\%, 15\% and 20\% Reconstituted
Skim Milk (RSM). EPS extracted from Alcaligenes faecalis var. myxogenes were added to RSM in different concentration $(0 \%$, $0.2 \%, 0.4 \%, 0.6 \%, 0.8 \%$ and $1.0 \%$ ). The suspensions were heated at $60^{\circ} \mathrm{C}$ for 30 minutes and $85^{\circ} \mathrm{C}$ for 30 seconds.

\section{Physical Properties Measurement}

Viscosity of milk gel was measured using a viscometer (Tokimec Inc., Visconic EDModel). Steady shear rate of 100/ second along with a MK 50 rotor assembly and NV sensor system operating at $25^{\circ} \mathrm{C}$. Viscosity is expressed as millipascals per second.

After the determination of the viscosity, sample was homogenized with a mixer (Nikon Seiki BM-3 Model) and $\mathrm{pH}$ values were measured by using a TOAHM-30 pH-meter.

\section{Microstructure of Milk Gel}

Skim Milk Agar plate was made for making sample that examines microstructure. Gluing $4 \times 10 \mathrm{~mm}$ glass rods to inside surface of a petridish cover made a template. A $3 \%$ agar solution $\left(60^{\circ} \mathrm{C}\right)$ was poured to depth of $13 \mathrm{~mm}$ into the petrel dish. The template was then placed into the agar solution. The template was removed after the agar had solidified, which resulted in the formation of cylindrical pores in the agar. The milk gel was then pipetted into the pores. The surface was overlaid with $3 \%$ agar, which had been tempered to $45^{\circ} \mathrm{C}$. After the agar overlay had solidified, $6 \mathrm{~mm}$ cubes containing a single cylindrical pore of milk gel were cut out of the agar. The agar cubes were fixed in $2.5 \%$ glutaraldehyde solution buffered at $\mathrm{pH} 7.0$ with $0.1 \mathrm{M}$ phosphate buffer, and then post fixed in $1 \%$ osmium tetraoxide solution. Samples were dehydrated in a graded alcohol series (50\%, 60\%, 70\%, 80\%, 95\%, and 99.5\%), and the dried in Hitachi HCP-2, ion type sputter coated (Hitachi Ltd, 
Tokyo), and viewed in a Hitachi s-4 100 type scanning electron microscope.

\section{Results and Discussions}

The term "milk gel” refers to EPS was suspended in reconstituted skim milk and treaded by heat treatment to form gel before cooling.

Figure 1 is a typical viscosity of curdlan milk gel as a function of EPS concentrations at different concentrations of skim milk. Lower concentration of EPS, viscosity showed a slight increase, but at $0.4 \%$ of EPS concentration, viscosity increased rapidly and continued to increase up to $1 \%$. This model is the same as that in the Figure 2 (heated at $85^{\circ} \mathrm{C}$ ) showing that the viscosity increased linearly with increased EPS concentrations. Viscosity was also dependent on the concentration of RSM increased. This is probably as a result of globular proteins such as bovine serum albumin, $\beta$-lactoglobulin, and avalbumin can form gel on heating, indicating that there are some interaction forces that cause gelation. This formation was suspended by EPS, that is an important contribution by hydrophobic interaction to heat induced gelation.

The charges of $\mathrm{pH}$ as a function of EPS concentration in skim milk heated at $60^{\circ} \mathrm{C}$ and $85^{\circ} \mathrm{C}$ are shown in Figure 3 . There was little change in $\mathrm{pH}$ with increasing EPS concentration in skim milk $10 \%$ and $15 \%$ but $\mathrm{pH}$ was constant in $20 \%$ skim milk. This result indicated that swelling enthalpy is independent of the concentration of EPS, so milk dissolved in water gave milk a pH of about 6, 7 (Walstra \& Jennes, 1984). High concentrations of milk solid are known to produce an increase in the buffer capacity of milk. In general, the viscosity increased with lower $\mathrm{pH}$ and higher total solid.

The result above was supported by microstructure examination in Figure 4. Mixing EPS and casein particle result forma-

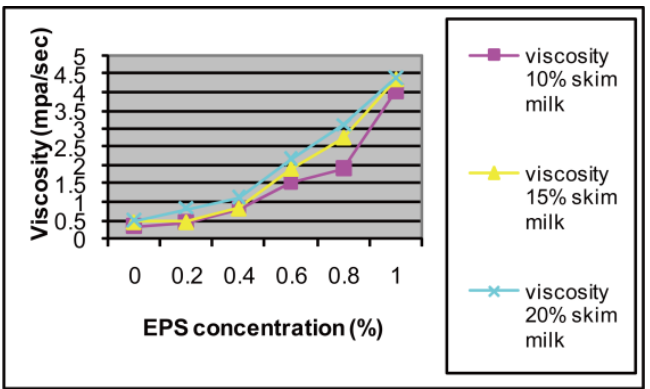

Figure 1.

Viscosity of EPS-milk gels, heated at $60^{\circ} \mathrm{C}$ for $30 \mathrm{~min}$.

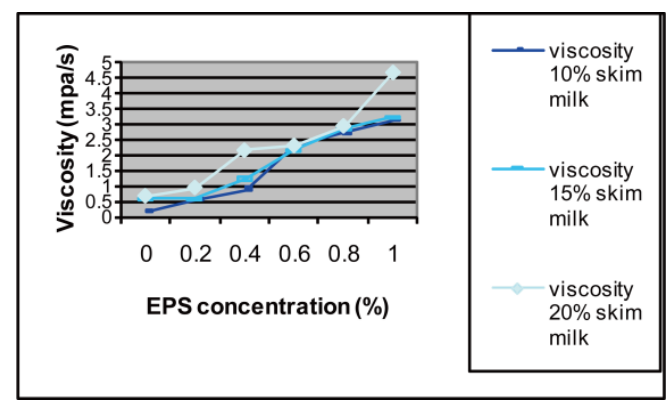

Figure 2.

Viscosity EPS-milk gel, heated at $85^{\circ} \mathrm{C}$ for $30 \mathrm{~s}$ in different concentration of skim milk.
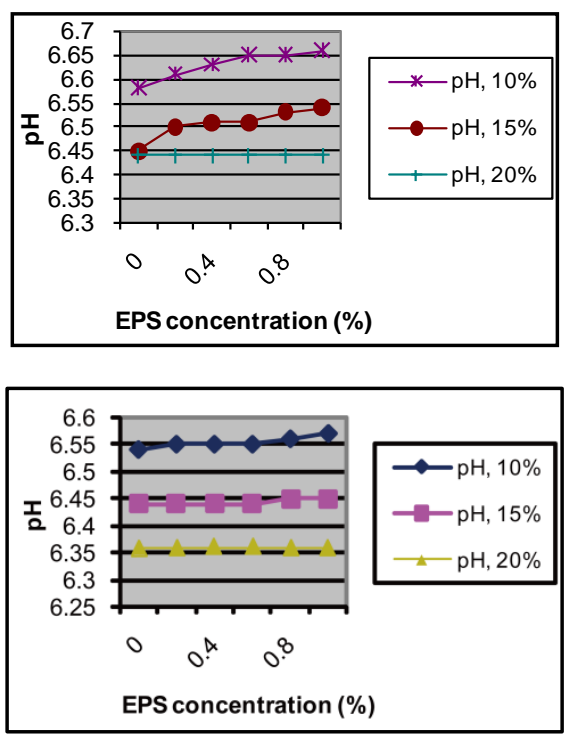

Figure 3.

$\mathrm{pH}$ of EPS-milk gel, heated at $6 \dddot{C}$ for $30 \mathrm{~min}$ (upper) and $85^{\circ} \mathrm{C}$ for $30 \mathrm{~s}$ (below).

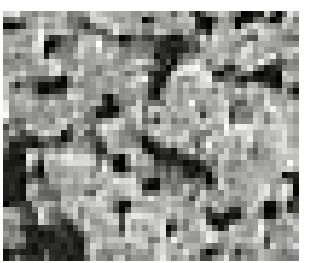

(a)

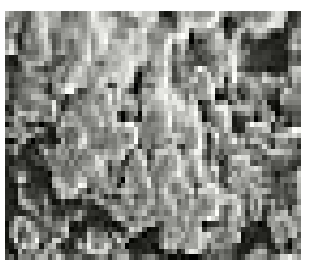

(c)

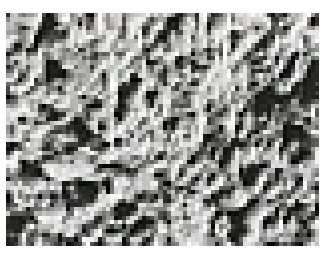

(e)

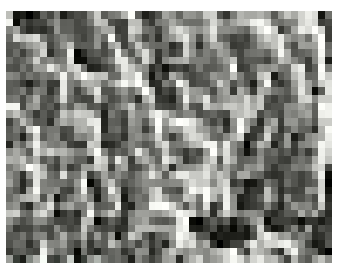

(b)

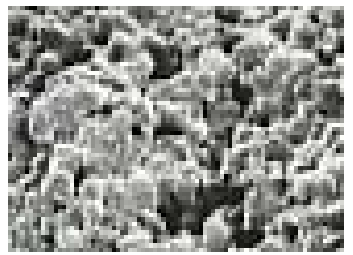

(d)

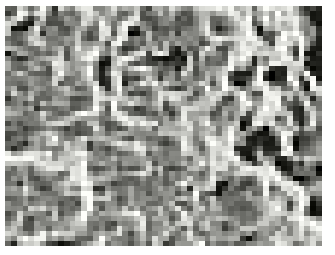

(f)
Figure 4.

Microstructure of EPS milk gel in different concentration of EPS; (a) $=0 \%$ of EPS; (b) $=0.2 \%$ of EPS; (c) $=0.4 \%$ of EPS; $(d)=0.6 \%$ of EPS; (e) $=0.8 \%$ of EPS; (f) $=1.0 \%$ of EPS.

tion of necklace-like structure or aggregate like structure, where an extended network was formed with high molecular of EPS. A part of the EPS molecule is actually contacted with the surface of the casein particle. A part consisting of free loops and tails may interact with each other to form infinitive network or aggregates. An adsorbed EPS molecules, as is necessary for the formation of the three dimensional network when short chain of 
the molecules.

Goff et al., (1993) has been observed the influence of polysaccharide on the glass transient in ice cream. Polysaccharide stabilizers such as locust bean gum, guar gum, sodium carboxy methyl cellulose, sodium alginate, carrageenan, and xanthan are commonly added to ice cream to control ice crystal growth during hardening and storage, especially in abusive temperature, to give body and stiffness during freezing for air incorporation, and to impart smoothness in body and texture.

\section{Conclusion}

Addition of EPS as stabilizer in milk gel formation can increase the quality of the product. EPS reacted with casein micelles that formed polysaccharide-protein network aggregations.

\section{REFERENCES}

Goff, H. D., Caldwell, K. B., Stanley, D. W., \& Maurice, T. J. (1993).
The influence of polysaccharides on the glass transition in frozen sucrose solution and ice cream. Journal of Dairy Science, 76, 12681277. http://dx.doi.org/10.3168/jds.S0022-0302(93)77456-1

Malaka, R. (1997). Effect of curdlan, a bacteria polysaccharide on the physical properties and microstructure of acid milk curd by lactic acid fermentation. Master Thesis, Japan: Faculty of Agriculture, Miyazaki University.

Snoeren, T. H. M., Both, M. P., \& Smith, D. G. (1976). An electron microscopic study of carrageenan and its interaction with $\chi$-casein. Netherlands Milk and Dairy Journal, 30, 132-141.

Sutherland, I. W. (1977). Bacterial exopolysaccharide, their nature and production in: Surface carbohydrates of the prokaryotic cell (pp. 2796). New York: Academic Press.

Walstra, P., \& Jennes, R. (1984). Dairy chemistry and physics. New York: John Wiley and Sons.

Yoon, S. C., Yoshida, T., Mimura, T., Kaneko, Y., Nakashima, H., Yamamoto, Y., \& Uryu, T. (1996). Synthesis of sulfated octadecyl ribo-oligosaccharides with potent anti-AIDS virus activity by ringopening polymerization of a 1,4 anhydroribose derivate. Carbohydrate Research, 282, 113-123. 